\title{
Identificação dos Níveis de Degradação de Matas Ripárias com o Uso de SIG
}

\author{
Roseli Mendonça Dias ${ }^{1}$, Nemésio Neves Batista Salvador ${ }^{1}$, \\ Magno Botelho Castelo Branco ${ }^{2}$
}

${ }^{1}$ Programa de Pós-Graduação de Engenharia Urbana, Universidade Federal de São Carlos - UFSCar, São Carlos/SP, Brasil

${ }^{2}$ Iniciativa Verde - Organização da Sociedade Civil de Interesse Público - OSCIP, São Paulo/SP, Brasil

\begin{abstract}
RESUMO
O presente trabalho objetivou identificar níveis de degradação de matas ripárias com o emprego de Sistema de Informações Geográficas (SIG), para a determinação das categorias de degradação encontradas na Unidade de Gerenciamento de Recursos Hídricos do TietêJacaré, no município de São Carlos-SP. O método consistiu na interpretação visual de imagens de satélite Landsat 5 da área de estudo, em amostragens de campo e no desenvolvimento de procedimentos para a classificação dos níveis de degradação de suas matas ripárias. Foi gerado um mapa das categorias de degradação das matas ripárias, o que permitiu avaliar os locais degradados, com floresta e em estágios de regeneração. A interpretação de imagens de satélite para a identificação dos níveis de degradação das matas ripárias apresenta-se como um instrumento útil para subsidiar informações sobre as matas ripárias das drenagens e nascentes de uma bacia hidrográfica. Outra possibilidade corresponde ao monitoramento do desenvolvimento da degradação ou da recuperação destas matas.
\end{abstract}

Palavras-chave: Área de Preservação Permanente, imagem de satélite, bacia hidrográfica, mata ripária.

\section{Identification of Level of Degradation of Riparian Forest with the Use of GIS}

\begin{abstract}
The objective of this study is to identify degradation levels of the riparian forests using Geographic Information System (GIS) to determine the categories of degradation found in the Unit for Water Resources Management of the Tietê-Jacaré in the city of São Carlos - SP, Brazil. The method consisted in the use of visual interpretation of satellite images Landsat 5 of the study area, field samplings and the development of procedures to classify the degradation levels of the riparian forests. A map of the degradation categories of the riparian forests was generated, which provided evaluating degraded sites, with forest and regeneration stages. The interpretation of satellite images to identify the degradation levels of the riparian forests is presented as a good instrument to subsidize information on the riparian forests of the drainages and headwaters of a watershed. Another possibility corresponds to monitoring the development of degradation or recovery of those forests.
\end{abstract}

Keywords: Permanent Preservation Areas, satellite image, watershed, riparian forest. 


\section{INTRODUÇÃO}

O modelo atual de desenvolvimento exerce uma pressão cada vez maior sobre as florestas, principalmente sobre as matas ripárias, responsáveis pela proteção dos recursos hídricos, pela manutenção das margens dos corpos d'água e pela contribuição para uma melhor qualidade de vida para a população sob a influência de uma bacia hidrográfica.

As formações ripárias são entendidas como os diversos tipos de vegetação arbórea vinculada às margens de cursos d'água (Ab’Sáber, 2001).

Visando à proteção dessas áreas, em 1965, o Código Florestal (Brasil, 1965), em seu Art. 1º, inciso II, incluído pela Medida Provisória n ${ }^{\circ}$ 2.16667 de 2001 (Brasil, 2001), definiu como Área de Preservação Permanente:

Área protegida nos termos dos arts. $2^{\circ}$ e $3^{\circ}$ desta Lei, coberta ou não por vegetação nativa e que tem a função ambiental de preservar os recursos hídricos, a paisagem, a estabilidade geológica, a biodiversidade, o fluxo gênico de fauna e de flora, proteger o solo e garantir o bem-estar das populações humanas. (Brasil, 2001, p. 1)

Nesse contexto, as matas ripárias fazem parte das Áreas de Preservação Permanente (APPs) de cursos d'água.

Segundo Gênova et al. (2007), a existência de vegetação no entorno dos corpos d'água auxilia as funções hidrológicas das bacias hidrográficas, tanto na qualidade quanto no regime de fluxo da água, sendo motivo de atenção em ações de planejamento e recuperação do ambiente ripário.

Os intensos processos de urbanização, a abertura de estradas, a construção de hidrelétricas, o cultivo agrícola, a formação de pastagens e até mesmo a visão de que seriam um obstáculo de acesso do gado ao curso d'água pelos produtores rurais são fatores que afetam as matas ripárias (Martins, 2007). O autor menciona que a degradação desta vegetação acarreta diversos problemas ambientais, visto que desobedece à legislação que obriga a preservação dessas matas.

Para a identificação da degradação das matas ripárias, as imagens de satélite são úteis instrumentos. A interpretação de imagens consiste em identificar objetos nestas contidos e apresentar um significado a esses objetos (Florenzano, 2002).
Elementos básicos de análise e interpretação das imagens, independentemente da resolução e da escala, são: tonalidade/cor, textura, tamanho, forma, sombra, altura, padrão e localização (Florenzano, 2002).

Como complementação aos elementos utilizados para interpretação das imagens de satélite, Ponzoni \& Shimabukuro (2007) salientam que o levantamento bibliográfico sobre a região de estudo e os trabalhos de campo, para maior confiabilidade no resultado da interpretação das imagens, tornam-se fundamentais.

A interpretação visual pode ser descrita como a ação de analisar uma imagem com a finalidade de identificar objetos e estabelecer avaliações sobre seus atributos (Novo, 2010).

Desse modo, este trabalho teve como objetivo identificar níveis de degradação de matas ripárias por meio de Sistema de Informações Geográficas (SIG) e classificá-los em categorias de degradação empregadas na Unidade de Gerenciamento de Recursos Hídricos (UGRHI) do Tietê-Jacaré, no município de São Carlos-SP, proporcionando, assim, subsídios para restauro florestal dessas matas.

$\mathrm{O}$ restauro florestal das áreas de mata ripária foi indicado como prioridade maior para o Comitê de Bacia da UGRHI do Tietê-Jacaré em seu Plano de Bacia, o que motivou a escolha desta como área de estudo (CPTI, 2008), como também a necessidade de preservação dessas áreas perante a intensa degradação que o uso e a ocupação do solo vêm ocasionando nessas áreas.

\section{MATERIAIS E MÉTODOS}

\subsection{Materiais}

Os equipamentos, imagens de satélite e softwares utilizados no desenvolvimento do trabalho estão listados a seguir:

- Equipamentos:

» Câmera digital da marca Samsung, de resolução 10.2 mega pixels;

» Aparelho GPS do modelo Garmin.

- Imagens de satélite:

» Landsat 5, Quickbird e Google Earth.

- Software:

» ArcGIS 10 


\subsection{Caracterização da área de estudo}

O estudo foi realizado nos limites da UGRHI do Tietê-Jacaré dentro do município de São Carlos, que está localizado na região central do Estado de São Paulo, entre as coordenadas $21^{\circ} 30^{\prime} \mathrm{S}, 47^{\circ} 30^{\prime}$ W e $22^{\circ} 30^{\prime} \mathrm{S}, 48^{\circ} 30^{\prime} \mathrm{W}$. Segundo o Censo de 2010 realizado pelo IBGE (2010), o município conta com uma população de 221.950 habitantes, em uma área de $1.137,303 \mathrm{~km}^{2}$.

O município de São Carlos situa-se na província geomorfológica das Cuestas Basálticas (Oliveira \& Prado, 1984), estando a malha urbana localizada no Planalto de São Carlos. O clima é do tipo Cwa, segundo a classificação de Koeppen, constituindo-se em um clima tropical de altitude com verão chuvoso e inverno seco. De acordo com o CEPAGRI (2012), a precipitação média é de 1.422,8 mm.

A vegetação, conforme mencionado por Soares et al. (2003) e Oliveira (1996), é formada por Florestas Semidecídua e Ripariana, Cerrado e Cerradão. Considerando-se o uso do solo, as principais atividades do município são a agropecuária, a mineração e o reflorestamento.

São Carlos está contido nas Bacias Hidrográficas Rio Tietê-Jacaré (BHTJ) e Rio Mogi-Guaçu (BHMogi). As Sub-Bacias Hidrográficas da BHTJ, dentro do município, são as do Rio Chibarro, do Rio Monjolinho, do Ribeirão do Feijão e do Rio JacaréGuaçu, perfazendo uma área de aproximadamente $470 \mathrm{~km}^{2}$ (Figura 1). Essas Sub-Bacias constituíram as áreas de inspeção exploratória da degradação das matas ripárias de alguns dos cursos d'água pertencentes às malhas hídricas das mesmas.

\subsection{Desenvolvimento do trabalho}

O trabalho consistiu na identificação dos níveis de degradação das matas ripárias na área de estudo e na classificação destes em categorias de degradação, a seguir:

- Arbóreo fechado

- Arbóreo-arbustivo aberto

- Herbáceo predominante

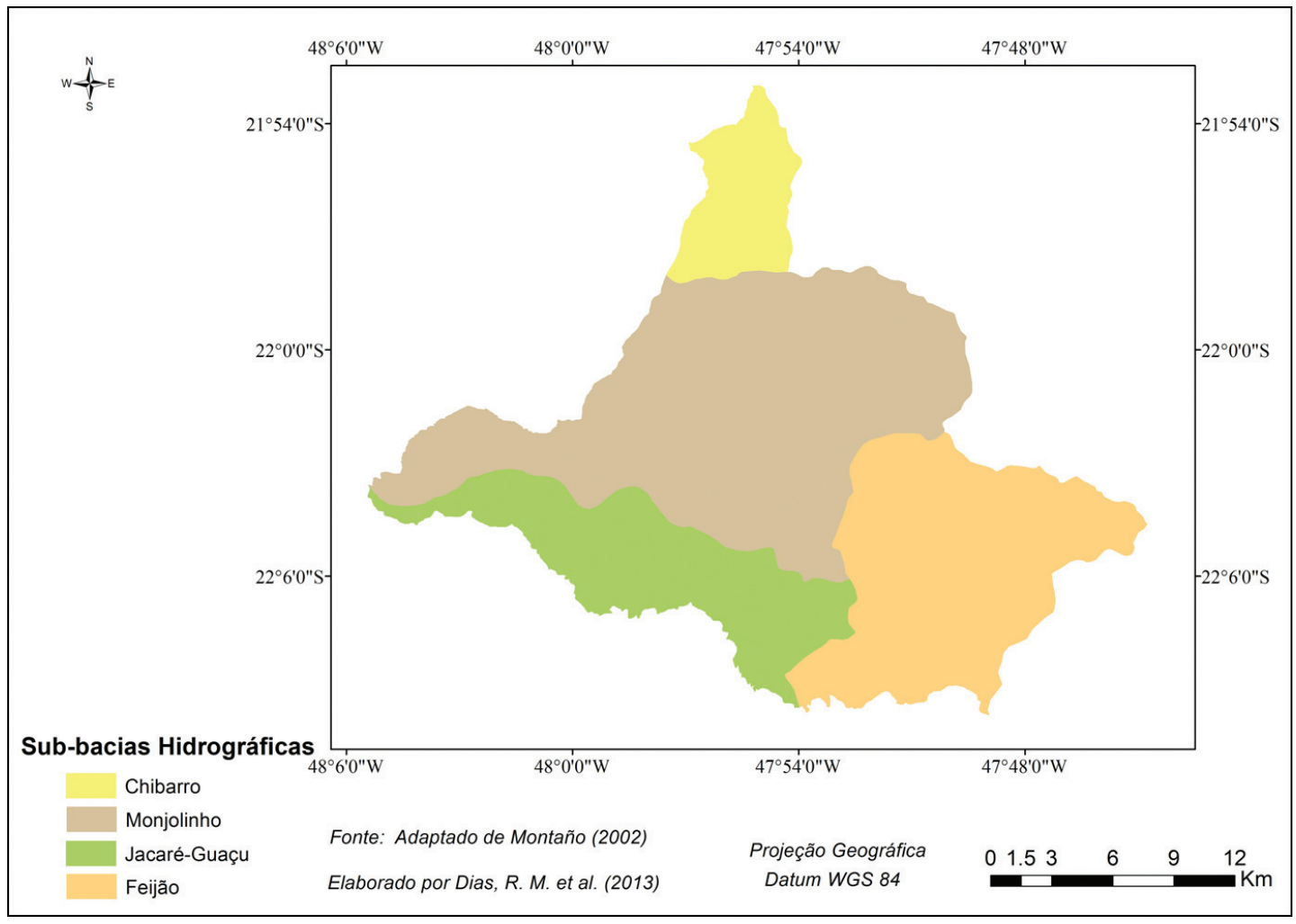

Figura 1. Sub-Bacias Hidrográficas da área de estudo.

Figure 1. Subwatershed study area. 
A categoria arbóreo fechado enquadrou as áreas de floresta estacional semidecidual e em estágio de regeneração; a arbóreo-arbustivo aberto enquadrou as áreas de capoeira sem predominância arbórea e áreas com gramíneas e apenas algumas árvores; e a herbáceo predominante enquadrou áreas de campo e área aberta.

Inicialmente, foram levantadas todas as informações disponíveis para o estudo por meio da revisão bibliográfica e foi elaborado o banco de dados para a análise da degradação das matas ripárias, utilizando o software ArcGIS 10 (ESRI, 2013). Obteve-se o arquivo digital, em formato shape, contendo a hidrografia da área de estudo, a qual foi digitalizada a partir das Cartas do IBGE na escala 1:50.000.

Em seguida, foram gerados os buffers de APP de cursos d'água sobre a drenagem, as nascentes $\mathrm{e}$ as represas. Os limites para as faixas de APPs foram aqueles estabelecidos no Código Florestal em seu Art. $4^{\circ}$ (Brasil, 2012).

Foi utilizada uma imagem da área do satélite Landsat 5 ano de 2011, obtida do INPE (2012). A fim de corrigir as diferenças geométricas da imagem, ou seja, os deslocamentos desta, foi realizado o seu georreferenciamento. Fez-se a composição das Bandas Espectrais TM3, TM4 e TM5, tornando a imagem colorida. Isso permitiu também a aplicação do Índice de Vegetação da Diferença Normalizada - NDVI, para melhor identificação da presença de vegetação na área de estudo.

Para a aplicação do NDVI, foram utlizadas as Bandas Espectrais TM4 (região espectral do infravermelho próximo) e TM3 (região espectral do visível), aplicadas na Equação 1.

Float (Band_4 - Band_3) / Float (Band_4 + Band_3)
Como complementação, foram utilizadas imagens do satélite Quickbird de resolução espacial de $61 \mathrm{~cm}$ e $50 \mathrm{~cm}$ dos anos de 2008 e 2010, de uma parcela da área de estudo, fornecidas pelo Serviço Autônomo de Água e Esgoto (SAAE) de São Carlos.

Imagens do Google Earth referentes ao intervalo anual de 2004 a 2012 também foram utilizadas como complemento à imagem Landsat 5 .

Posteriormente, foi realizada uma interpretação visual das imagens, considerando-se os elementos tonalidade/cor, textura, tamanho, forma, sombra, altura, padrão e localização, o que orientou a coleta de pontos de controle que serviram de referência e proporcionou um ajuste para a classificação das categorias de degradação das matas ripárias.

Foram escolhidos pontos de controle nas quatro Sub-Bacias hidrográficas da BHTJ, permitindo o georreferenciamento de toda a área de estudo.

Parcelas de diferentes tamanhos, adaptadas de Macdicken (1997), foram estabelecidas para os pontos de controle escolhidos, de modo a definir o porte da vegetação. Este autor estabeleceu tamanhos de parcelas circulares para vegetação densa, moderadamente densa, moderadamente esparsa, esparsa e muito esparsa (Tabela 1).

Em face a esta divisão de parcelas, fez-se uma adaptação das parcelas circulares em quadrantes. Desse modo, foi possível fixar os níveis de degradação conforme o número de árvores em cada uma das áreas escolhidas. Para cada uma das categorias de degradação definidas para este trabalho, foram adaptadas as aplicabilidades apresentadas na Tabela 1. Fotografias dos locais possibilitaram também a classificação das categorias de degradação, bem como as imagens de satélite utilizadas, com zoom nas regiões de interesse.

Tabela 1. Tamanho de parcelas.

Table 1. Size of fragments.

\begin{tabular}{ccc}
\hline Parcela $\left(\mathbf{m}^{\mathbf{2}}\right)$ & Área por árvore $\left(\mathbf{m}^{\mathbf{2}} / \mathbf{a} \mathbf{r v o r e}\right)$ & Aplicabilidade \\
100 & $0-15$ & Vegetação densa, muitas árvores \\
250 & $15-40$ & Vegetação moderadamente densa \\
500 & $40-70$ & Vegetação moderadamente esparsa \\
666,7 & $70-100$ & Vegetação esparsa \\
1000 & $>100$ & Vegetação muito esparsa \\
\hline
\end{tabular}

Fonte: Adaptado de Macdicken (1997). 
A posse de todas as informações descritas propiciou a análise da degradação das matas ripárias da drenagem e das nascentes e represas da área de estudo, possibilitando a divisão em categorias de degradação dos buffers de APP gerados.
Ao final desta etapa, foi confeccionado o Mapa das Categorias de Degradação das Matas Ripárias.

A Figura 2 apresenta as etapas executadas neste trabalho.

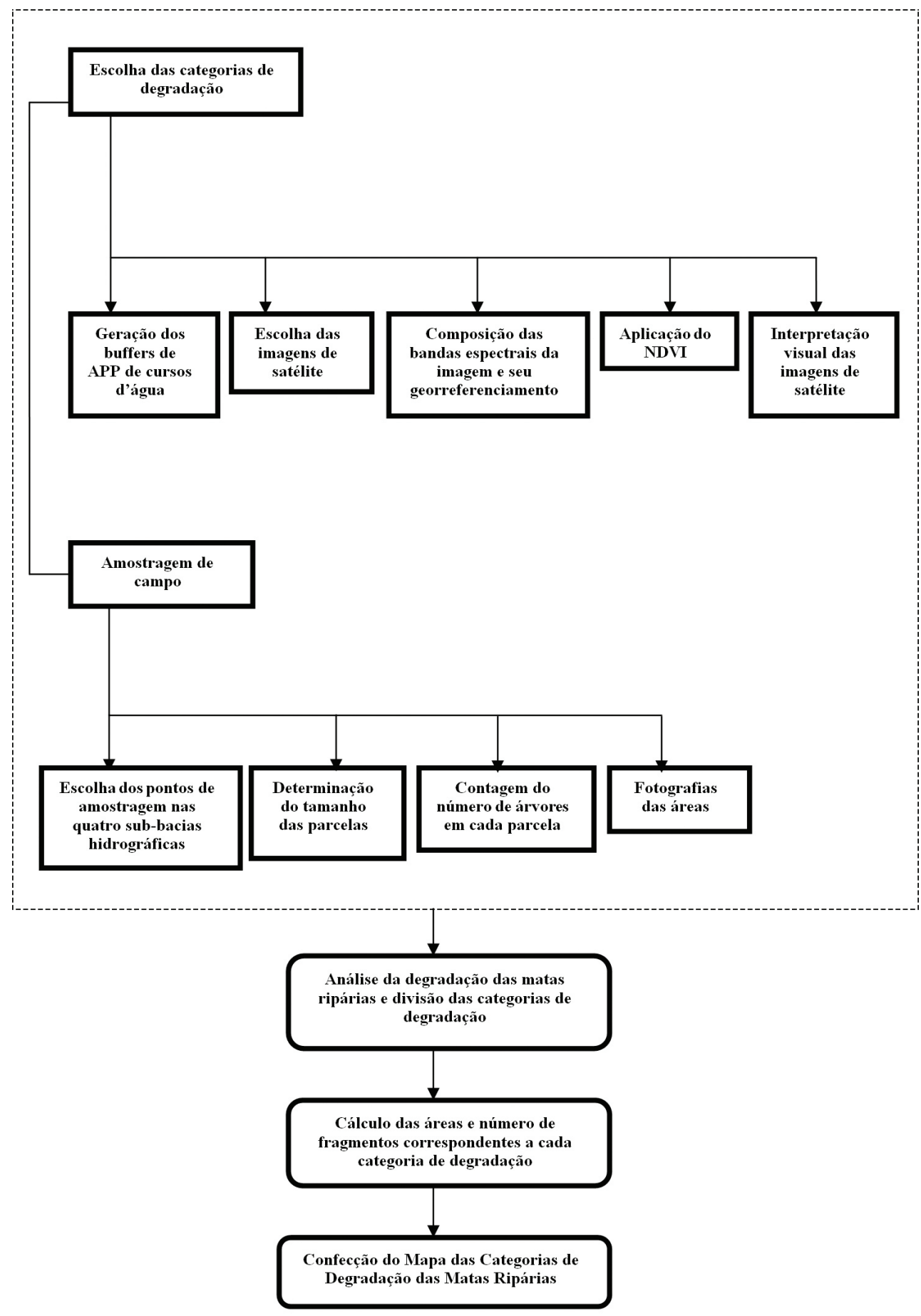

Figura 2. Fluxograma com as etapas do trabalho.

Figure 2. Flowchart with study steps. 


\section{RESULTADOS E DISCUSSÃO}

A inspeção exploratória das matas ripárias nas Sub-Bacias da área de estudo permitiu uma análise satisfatória dos locais escolhidos para a amostragem de campo, a qual aconteceu nos meses de agosto, outubro e novembro de 2012.

Na Sub-Bacia do Rio Chibarro, foram realizadas duas amostragens, que contaram 33 e 32 indivíduos (árvores) em uma parcela de $100 \mathrm{~m}^{2}$. Nos termos utilizados por Macdicken (1997), a vegetação apresenta-se densa.

Nas Figuras de 3 a 6, observam-se matas ripárias, junto às margens dos cursos d'água da Sub-Bacia do Rio Chibarro, conservadas e em degradação.

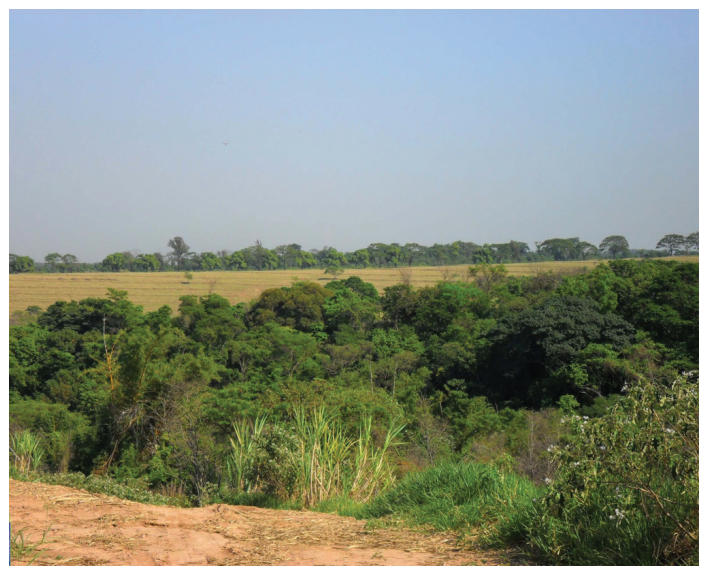

Figura 3. Mata ripária em estágio de regeneração. Figure 3. Riparian forest regeneration stage.

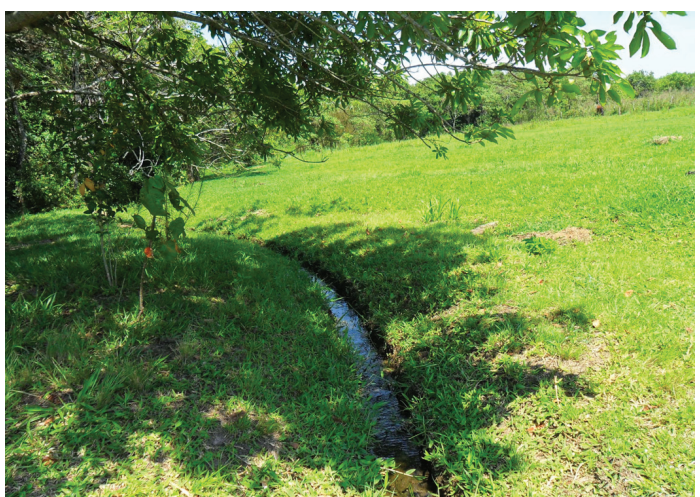

Figura 4. Local sem solo exposto e coberto por gramíneas.

Figure 4. Site without exposed soil and covered with grasses.
Na Sub-Bacia do Rio Monjolinho, a amostragem realizada em uma nascente, considerando uma parcela de $100 \mathrm{~m}^{2}$, encontrou 31 indivíduos; portanto, esta encontra-se conservada.

As Figuras de 7 a 10 apresentam córregos da Sub-Bacia do Rio Monjolinho, com mata ripária degradada e uma nascente conservada.

Na Sub-Bacia do Ribeirão do Feijão, duas amostras foram realizadas, apresentando 19 e 20 indivíduos em duas parcelas de $100 \mathrm{~m}^{2}$ cada. Em uma parcela de $1.000 \mathrm{~m}^{2}$, foram encontrados 55 indivíduos, o que significa que a vegetação é muito esparsa.

Nas Figuras de 11 a 14, notam-se algumas matas ripárias da Sub-Bacia do Ribeirão do Feijão conservadas, porém outras com degradação.

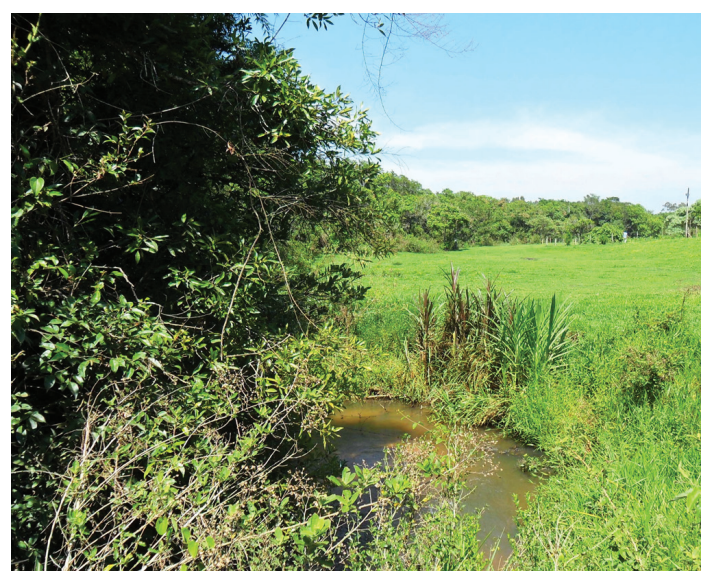

Figura 5. Local sem solo exposto e coberto por gramíneas e algumas árvores.

Figure 5. Site without exposed soil and covered with grass and some trees.

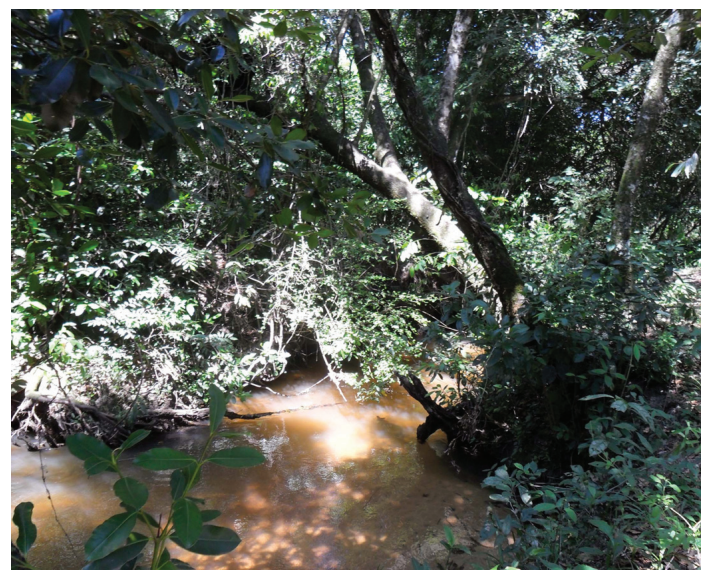

Figura 6. Mata ripária do Rio Chibarro.

Figure 6. Riparian forest River Chibarro. 


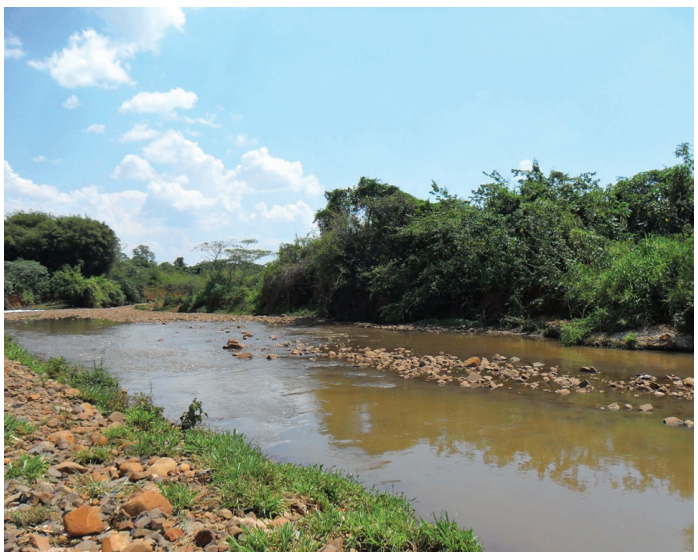

Figura 7. Trecho do Rio Monjolinho sem mata ripária em uma das margens.

Figure 7. River Monjolinho without riparian forest margins.

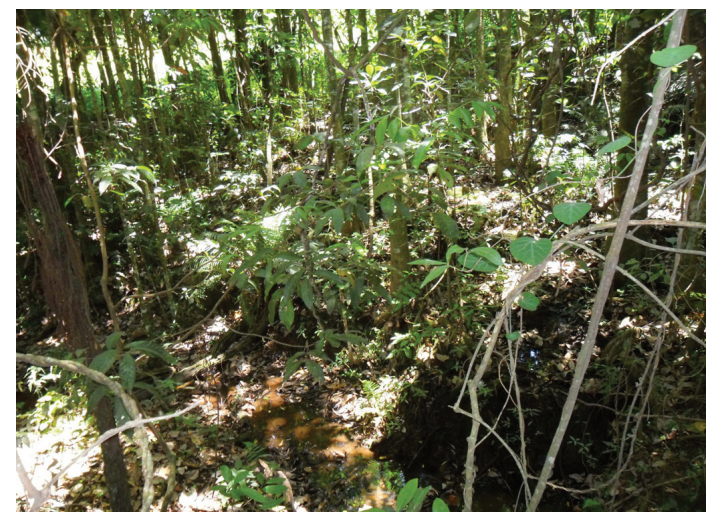

Figura 8. Nascente com mata ripária conservada. Figure 8. Headwater riparian forest conserved.

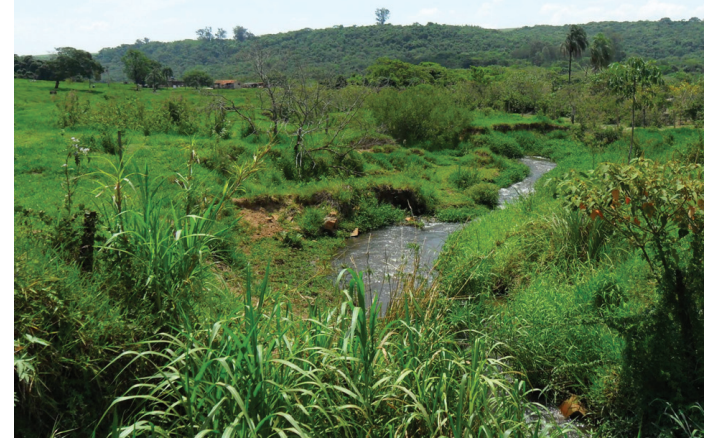

Figura 9. Córrego sem mata ripária conservada. Figure 9. Stream without riparian forest conserved.

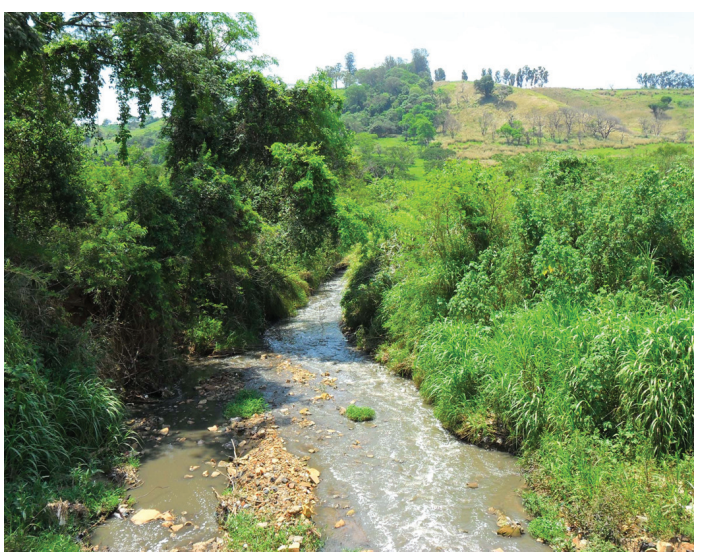

Figura 10. Córrego com presença de algumas árvores na APP.

Figure 10. Stream with some trees in PPA.

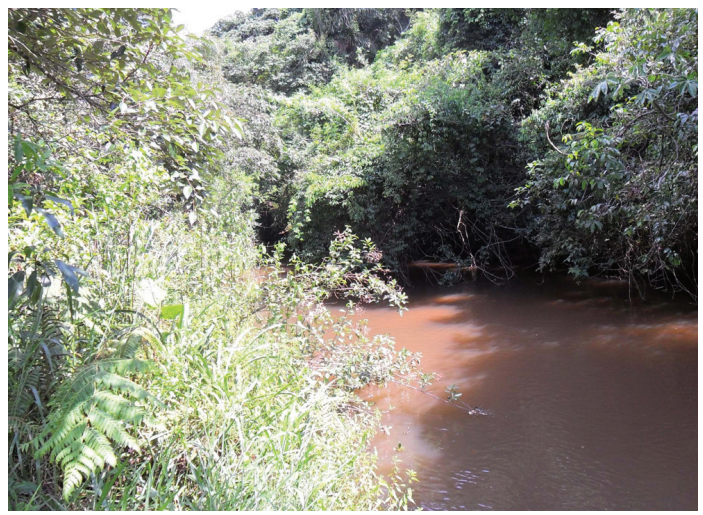

Figura 11. Mata ripária do Ribeirão do Feijão.

Figure 11. Riparian forest stream Feijão.

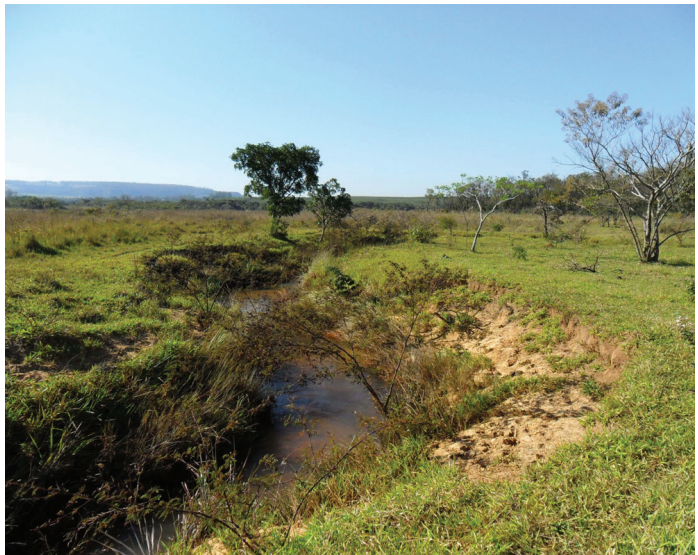

Figura 12. Córrego com solo exposto na APP Figure 12. Stream with exposed soil in PPA 


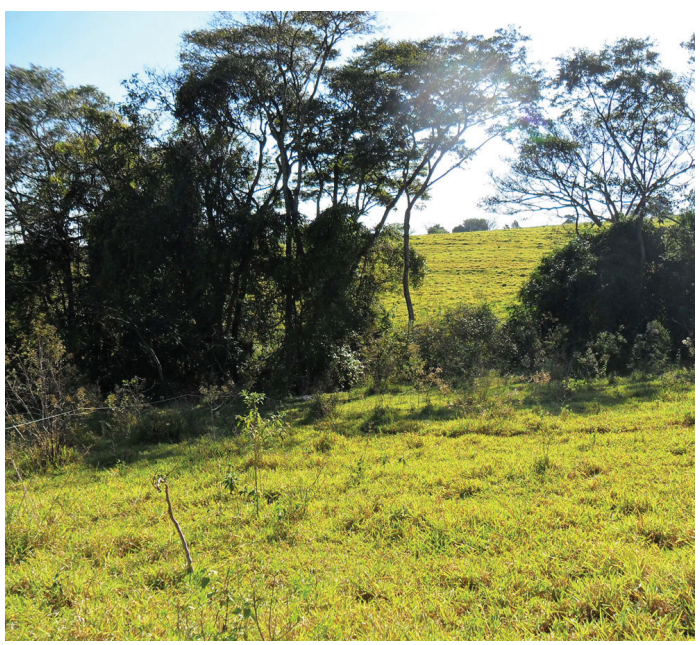

Figura 13. Mata ripária com gramíneas e algumas árvores.

Figure 13. Riparian forest with grasses and some trees.

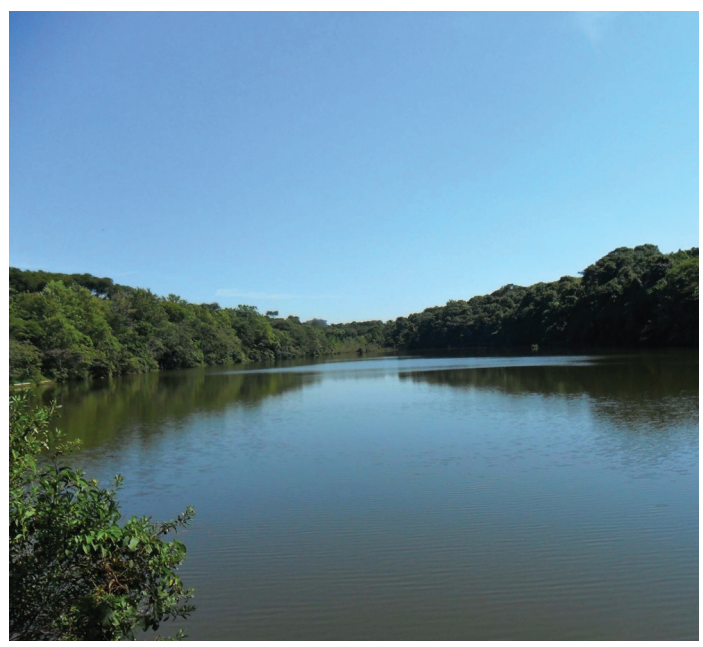

Figura 14. Represa com APP conservada.

Figure 14. Pond with PPA conserved.

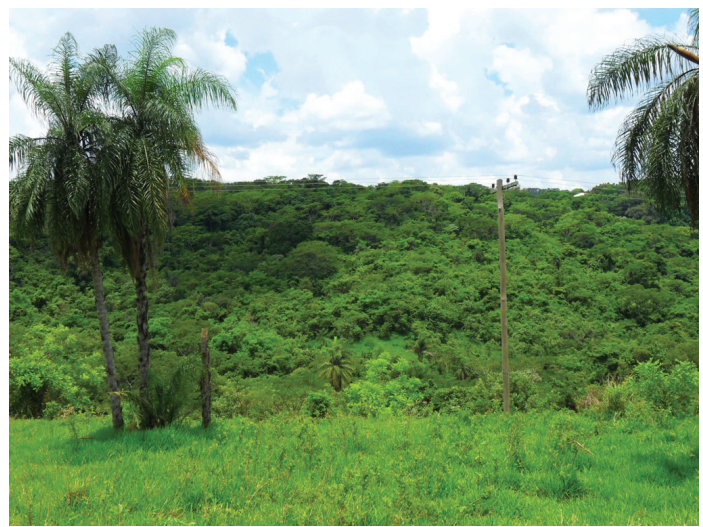

Figura 15. Mata ripária de difícil acesso.

Figure 15. Riparian Forest inaccessible.

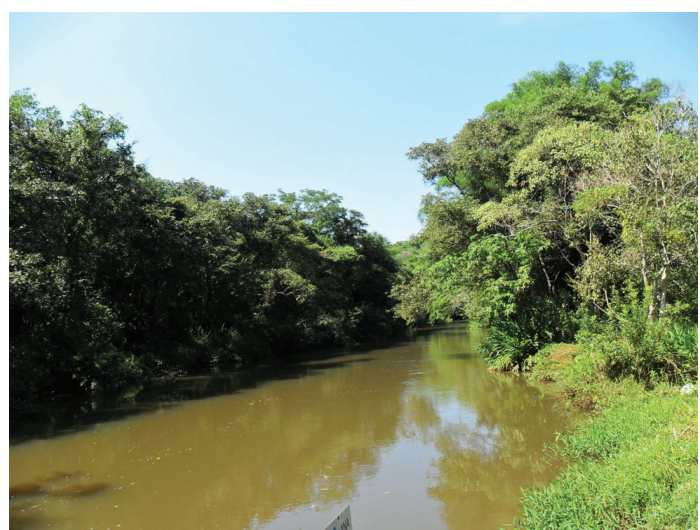

Figura 16. Rio Jacaré-Guaçu.

Figure 16. River Jacaré-Guaçu.

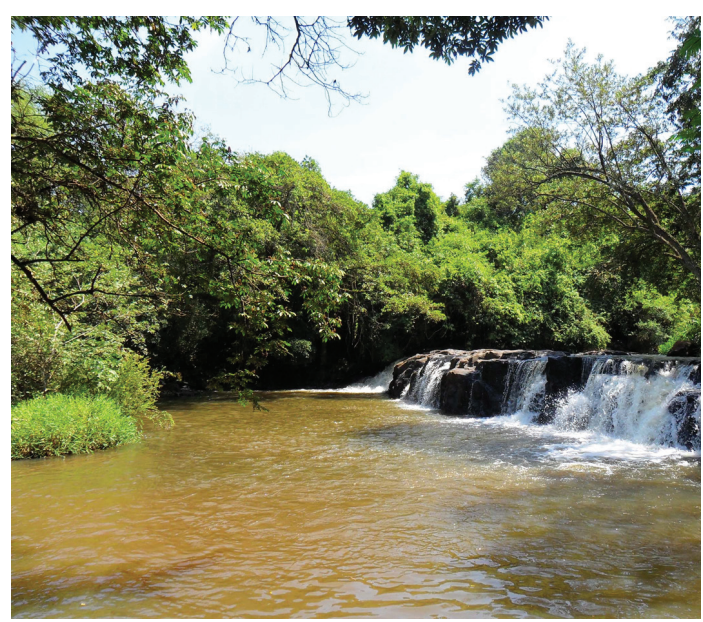

Figura 17. Cachoeira em APP preservada. Figure 17. Waterfall in PPA preserved.

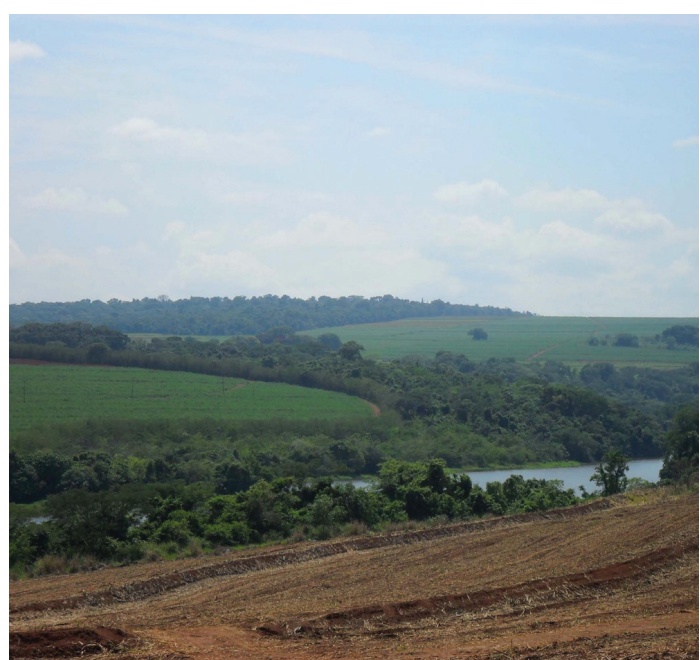

Figura 18. Fragmentos de mata ripária.

Figure 18. Fragments riparian forest. 
Devido ao nível de conservação das matas ripárias na Sub-Bacia do Rio Jacaré-Guaçu, alguns locais eram e são de difícil acesso, não sendo possível adentrar nas APPs para realizar uma amostragem.

As Figuras 15 a 18 apresentam matas ripárias conservadas. Locais com mata ripária fechada são fáceis de serem encontrados nesta Sub-Bacia, sinal de muitos benefícios proporcionados ao corpo d'água, como manutenção das margens para contenção de processos erosivos, embora ao redor de alguns fragmentos a presença de canaviais seja marcante.

O NDVI foi gerado com a intenção de colaborar na identificação da vegetação das matas ripárias da área de estudo.

A interpretação visual das imagens de satélite e do NDVI, e a amostragem de campo com os pontos de controle nas Sub-Bacias da área de estudo permitiram a confecção do Mapa das Categorias de Degradação das Matas Ripárias da BHTJ, no município de São Carlos (Figura 19).
Com base na análise visual do mapa, é possível notar que, na região sul da área de estudo, há mais APPs com florestas e fitofisionomias em estágio de regeneração, enquanto na região leste, há mais APPs degradadas por retirada das matas ripárias de córregos e nascentes.

Nota-se que a degradação está mais concentrada nas nascentes e nos cursos d'água próximos a estas, como também próxima aos locais antropizados, devido à supressão das matas ripárias, o que permitirá direcionar as políticas públicas do município.

Vale destacar que o principal manancial superficial do município é o Ribeirão do Feijão. Portanto, é de grande interesse a conservação da mata ripária desse manancial para fins de qualidade da água.

O Ribeirão do Feijão, ao sul, apresenta trechos com as categorias arbóreo fechado e arbóreoarbustivo aberto, o que caracteriza que alguns trechos estão degradados.

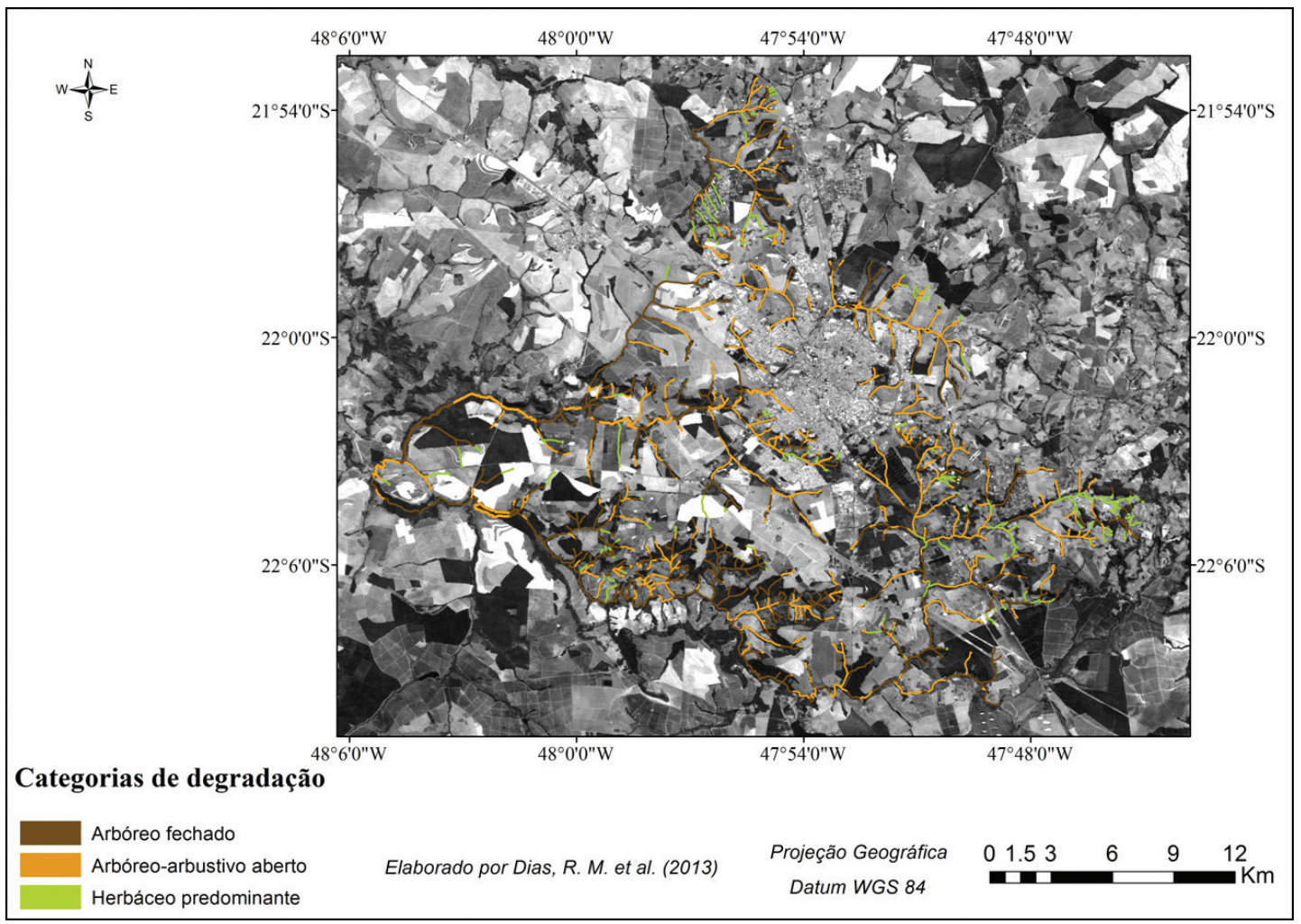

Figura 19. Mapa das Categorias de Degradação das Matas Ripárias da área de estudo.

Figure 19. Map Categories Degradation of the Riparian Forests in the study area. 
O Rio Jacaré-Guaçu, também ao sul, é o rio que se encontra com melhor estado de conservação, apresentando várias APPs com matas fechadas ou em estágios de regeneração.

Ressalta-se que a zona urbana do município concentra-se na Sub-Bacia do Rio Monjolinho, onde alguns córregos foram canalizados, retirando-se as suas matas ripárias.

As APPs que deveriam existir nesses locais ocupados, mas que foram suprimidas, correspondem a aproximadamente 115,52 ha. Assim, essas APPs não foram consideradas na divisão das categorias de degradação.

A Tabela 2 apresenta as categorias consideradas neste trabalho com os respectivos valores de área. A Figura 20 retrata os valores das áreas de cada categoria em porcentagem.

Assim, foram encontrados aproximadamente 1.378,39 ha de matas ripárias com predominância arbórea fechada e fitofisionomias em regeneração, sendo $41 \%$ das APPs consideradas não degradadas ou em estado de regeneração.

Para a categoria arbóreo-arbustivo aberto, aproximadamente $1.630,18$ ha, que correspondem a

Tabela 2. Informações sobre as categorias de degradação das matas ripárias.

Table 2. Information on categories of degradation of the riparian forests.

\begin{tabular}{|cc|}
\hline Categorias de degradação & Área (ha) \\
\hline Arbóreo fechado & $1.378,39$ \\
\hline Arbóreo-arbustivo aberto & $1.630,18$ \\
\hline Herbáceo predominante & 388,38 \\
\hline Total & $\mathbf{3 . 3 9 6 , 9 5}$ \\
\hline
\end{tabular}

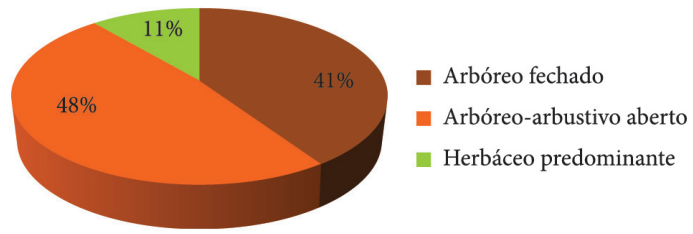

Figura 20. Gráfico com as porcentagens de cada categoria de degradação das matas ripárias da área de estudo.

Figure 20. Graphic with the percentages of each category of degradation of the riparian forests in the study area.
48\% das APPs, encontram-se sem a predominância de florestas fechadas, o que não constitui uma situação ideal para APPs nos termos da legislação ambiental; portanto, estas são consideradas áreas perturbadas ou degradadas.

Diversamente, as APPs com predominância de vegetação herbácea totalizaram aproximadamente 388,38 ha, ou seja, 11\% de APPs degradadas, cujas matas ripárias foram suprimidas.

As áreas de mata ripária prioritárias da UGRHI do Tietê-Jacaré no município de São Carlos para o restauro florestal são as que se enquadram na categoria herbáceo predominante. Essas áreas requerem maior atenção devido ao déficit de vegetação de porte arbóreo.

Alguns autores realizaram trabalhos similares. Os resultados apresentados neste trabalho podem ser comparados aos resultados de Gomes et al. (2011). Os autores utilizaram técnicas de processamento digital de imagens de satélite para confecção de mapas temáticos dos níveis de degradação da cobertura vegetal na área da Bacia Hidrográfica do Rio Jaibaras, no Estado do Ceará, assim como trabalho de campo. A cobertura vegetal foi classificada em vegetação conservada, parcialmente degradada, degradada, fortemente degradada e solo exposto. Os mesmos autores constataram, na área de estudo, a evolução dos níveis de degradação, com tendência de crescimento nas áreas de solo exposto e diminuição das outras classes de vegetação, ressaltando a vegetação conservada.

Os resultados do trabalho de Candido et al. (2010) também são similares aos resultados deste trabalho. Os autores produziram um mapa de degradação ambiental para a Bacia Hidrográfica do Rio Uberada, situada no Triângulo Mineiro, contendo os níveis de degradação baixo, moderado, acentuado e severo. A partir da interpretação visual de imagens de satélite, trabalho de campo e confecção de mapas, os autores puderam avaliar a degradação ambiental da área de estudo, destacando as áreas com nível de degradação ambiental acentuado, as quais ocupam a maior extensão dessa Bacia Hidrográfica.

Moraes Neto et al. (2002) classificaram as principais áreas degradadas das regiões oeste e norte da cidade de Campina Grande, no Estado da Paraíba. Os autores fizeram uso de processamento digital de 
imagem de satélite, interpretação visual e dados de trabalho de campo. O estudo indicou áreas que se encontram em estado avançado de degradação.

Assim, fica clara a importância do uso de metodologias de interpretação de imagens de satélite em SIG como subsídio para trabalhos similares em outras regiões, que apresentem condições semelhantes.

\section{CONCLUSÕES}

A interpretação de imagens de satélite para a identificação dos níveis de degradação das matas ripárias da área de estudo apresenta-se como um instrumento favorável para subsidiar informações sobre as matas ripárias das drenagens e nascentes de uma bacia hidrográfica, como também um monitoramento do desenvolvimento da degradação ou recuperação destas. Isso permite um maior planejamento nas decisões do Comitê em prol de benefícios para a bacia em questão.

A identificação da degradação das matas ripárias por meio de SIG, portanto, proporciona subsídios para a preservação das mesmas por parte dos proprietários rurais e gestores do município.

Uma das alternativas de financiamento para a recuperação das áreas degradadas de mata ripária é o restauro florestal com fins de sequestro florestal de carbono, de modo a subsidiar os projetos de recuperação e incentivar os proprietários rurais a realizar tais projetos, cumprindo a legislação ambiental brasileira.

\section{AGRADECIMENTOS}

Ao Allan Yu, pelo auxílio com o sensoriamento remoto. À CAPES, pela concessão de Bolsa de Mestrado à primeira autora. À Prof. a Adriana Pires do Departamento de Ciências Ambientais da UFSCar e ao Dirceu Azzolini Filho do SAAE de São Carlos, pela disponibilização de informações.

\section{STATUS DA SUBMISSÃO}

Recebido: 20 out., 2013

Aceito: 02 abr., 2014

Publicado: 30 jun., 2014

\section{AUTOR(ES) PARA CORRESPONDÊNCIA} Roseli Mendonça Dias

Programa de Pós-Graduação de Engenharia

Urbana, Universidade Federal de São

Carlos - UFSCar, CEP 13565-905, São Carlos, SP,

Brasil

e-mail: roose_mendonca@yahoo.com.br

\section{REFERÊNCIAS}

Ab’Sáber AN. O suporte geoecológico das florestas beiradeiras (ciliares). In: Rodrigues RR, Leitão HF Fo, editores Matas ciliares: conservação e recuperação. São Paulo: EdUSP; 2001.

Brasil. Lei n. 4.771, de 15 de setembro de 1965. Institui o Código Florestal. Diário Oficial da União, Brasília, DF (1965 set. 16); Sec. 1. [cited 2011 Fev. 09]. Available from: http://www.planalto.gov.br/ccivil_03/leis/L4771. htm.

Brasil. Medida Provisória no $2.166-67$, de 24 de agosto de 2001. Altera os arts. 1, 4, 14, 16 e 44, e acresce dispositivos à Lei n. 4.771, de 15 de setembro de 1965, que institui o Código Florestal, bem como altera o art. 10 da Lei n. 9.393, de 19 de dezembro de 1996, que dispõe sobre o Imposto sobre a Propriedade Territorial Rural - ITR, e dá outras providências. Diário Oficial da União, Brasília, DF (2001 ago. 24); Sec. 1. [cited 2011 Fev. 09]. Available from: https://www.planalto.gov.br/ ccivil_03/MPV/2166-67.htm

Brasil. Lei n. 12.651, de 25 de maio de 2012. Dispõe sobre a proteção da vegetação nativa; altera as Leis $\mathrm{n}$. 6.938, de 31 de agosto de 1981, 9.393, de 19 de dezembro de 1996, e 11.428, de 22 de dezembro de 2006; revoga as Leis ${ }^{\circ} 4.771$, de 15 de setembro de 1965 , e 7.754, de 14 de abril de 1989, e a Medida Provisória no 2.166-67, de 24 de agosto de 2001; e dá outras providências. Diário Oficial da União, Brasília, DF (2012 maio 25). [cited 2012 out. 26]. Available from: http://www.planalto.gov. br/ccivil_03/_Ato2011-2014/2012/Lei/L12651.htm.

Candido HG, Galbiatti JA, Pissarra TCT, Martins MV Fo. Degradação ambiental da bacia hidrográfica do Rio Uberaba: uma abordagem metodológica. Engenharia Agrícola 2010; 30(1): 179-92. http://dx.doi.org/10.1590/ S0100-69162010000100019

Centro de Pesquisas Meteorológicas e Climáticas Aplicadas a Agricultura - CEPAGRI. Clima dos municípios paulistas. Campinas. [cited 2012 Nov. 18]. Available from: http://www.cpa.unicamp.br/outrasinformacoes/clima_muni_549.html.

Cooperativa de Serviços, Pesquisas Tecnológicas e Industriais - CPTI. Plano de Bacia da Unidade de Gerenciamento de Recursos Hídricos do TietêlJacaré (UGRHI 13). Osasco; 2008. 
Environmental Systems Research Institute - ESRI. ArcGIS professional GIS for the desktop: version 10 . Redlands; 2013.

Florenzano TG. Imagens de satélite para estudos ambientais. São Paulo: Oficina de Textos; 2002. PMid:12421608

Gênova KB, Honda EA, Durigan G. Processos hidrológicos em diferentes modelos de plantio de restauração de mata ciliar em região de Cerrado. Revista Instituto Florestal 2007; 19(2): 189-200.

Gomes DDM, Mendes LMS, Medeiros CN, Verissimo CUV. Análise multitemporal do processo de degradação da vegetação da bacia hidrográfica do Rio Jaibaras no Estado do Ceará. Geografia Ensino \& Pesquisa 2011; 15(2): 41-62.

Instituto Brasileiro de Geografia e Estatística - IBGE. Censo 2010. Rio de Janeiro; 2010.

Instituto Nacional de Pesquisas Espaciais - INPE. Imagens de satélite. São José dos Campos; 2012.

Macdicken KG. A guide to monitoring carbon storage in forestry and agroforestry projects. Arlington: Winrock International Institute for Agricultural Development; 1997. Forest Carbon Monitoring.

Martins SV. Recuperação de matas ciliares. Viçosa: CPT; 2007.
Moraes JM No, Barbosa MP, Fernandes MF, Silva MJ. Avaliação da degradação das terras nas regiões oeste e norte da cidade de Campina Grande, PB: um estudo de caso. Revista Brasileira de Engenharia Agrícola e Ambiental 2002; 6(1): 180-182. http://dx.doi. org/10.1590/S1415-43662002000100032

Novo EMLM. Sensoriamento remoto: princípios e aplicações. 4. ed. São Paulo: Blucher; 2010.

Oliveira JB, Prado H. Levantamento pedológico semidetalhado do Estado de São Paulo: quadrícula de São Carlos. Campinas: Instituto Agronômico; 1984. Memorial descritivo.

Oliveira CH. Planejamento ambiental na cidade de São Carlos (SP) com ênfase nas áreas públicas e áreas verdes: diagnóstico e propostas [dissertação]. São Carlos: Ecologia e Recursos Naturais, Universidade Federal de São Carlos; 1996.

Ponzoni FJ, Shimabukuro YE. Sensoriamento remoto no estudo da vegetação. São José dos Campos: Parêntese; 2007.

Soares JJ, Silva DW, Lima MIS. Current state and projection of the probable original vegetation of the São Carlos Region of São Paulo State, Brazil. Brazilian Journal of Biology 2003; 63(3): 527-536. http://dx.doi. org/10.1590/S1519-69842003000300019 